\title{
SEX MARKERS ON BIRTH \\ CERTIFICATES: REPLACING THE MEDICAL MODEL WITH SELF- IDENTIFICATION
}

\author{
Emily Blincoe*
}

Section 28 of the Births, Deaths, Marriages, and Relationships Registration Act 1995 allows people to apply to the Family Court to change the sex marker on their birth certificate. This article argues that this provision is outdated and does not go far enough in providing legal recognition for trans people. It is based on the medical model of sex, and requires medical evidence that the applicant's body conforms sufficiently to that of the "nominated sex". The major problem with this requirement is that the required medical interventions are unavailable or undesirable for many trans people, so should not be a basis for legal recognition. The medical model also privileges medical and judicial expertise above a person's own identity and experience. This article suggests a reform based on the self-identification model, which exists in Argentina for birth certificates, and in New Zealand for passports and drivers' licences. Such a reform of s 28 would bring birth certificates in line with these other documents, leading to more consistency and increased respect for the human rights of trans people.

\section{INTRODUCTION}

When a birth is registered, a sex is recorded on the birth certificate. This is the starting point of medical and legal classification of bodies into categories of female and male. Most people go through life identifying as the sex/gender assigned to them at birth; that is, they are cisgender. For example, I am a cisgender woman and so I have a birth certificate and other identity documents that match my identity. I do not have to prove anything about my genitals, chromosomes, hormones, lifestyle or behaviour in order to be legally (or socially) recognised as a woman. Trans people, whose identities do not match the sex assigned to them at birth, are frequently denied legal

* Submitted as part of the LLB(Hons) programme at Victoria University of Wellington. I would like to thank my supervisor, Associate Professor Elisabeth McDonald, for her invaluable support and guidance throughout the writing of this article. I would also like to thank Emily Haskell for her knowledge, advice and encouragement. 
recognition, or heavily scrutinised in order to attain it. One situation where trans people face particular scrutiny is in correcting the sex marker on their birth certificate. As a cisgender person this issue does not affect me and it is important to recognise that I am writing about it from a position of privilege. ${ }^{1}$ For trans people, however, legal recognition (or conversely the denial of it) has very real consequences.

The ability to change sex markers on birth certificates is of vital importance to some people. This includes trans people, who are: ${ }^{2}$

... those people who do not perceive or present their gender identity as the same as that expected of the group of people who were given the equivalent sex designation at birth.

I use "trans" as an umbrella term which encompasses a range of identities that fit this definition, including transgender and transsexual. ${ }^{3}$ In doing so I recognise that many people who could be described as trans do not identify with that term. For example, Māori may identify as whakawahine, hinehi, hinehua, or tangata ira tane, and Pasifika people may identify as fa'afafine (Samoa), fakaleiti (Tonga), akava'ine (Cook Islands), mahu (Hawaii), vaka sa lewa lewa (Fiji), rae rae (Tahiti) or fiafifine (Niue). ${ }^{4}$ These terms can only be understood within their cultural context and are not translations of English concepts. ${ }^{5}$

Sex and gender are contested terms which have in various contexts been both distinguished and equated by both the law and by trans people seeking legal recognition. ${ }^{6}$ In this article I focus on sex rather than gender because it is sex that is recorded on birth certificates, however I acknowledge that

1 For a discussion of cisgender privilege generally, see Julia Serano Whipping Girl: a Transsexual Woman on Sexism and the Scapegoating of Femininity (Seal Press, Emeryville, 2007) at ch 8.

2 Stephen Whittle Respect and Equality: Transsexual and Transgender Rights (Cavendash Publishing, London, 2002) at xxii.

3 These concepts are contested and debates about their meaning are outside the scope of this article. See Serano above n 1, at 25-27; and Dean Spade "Resisting Medicine, Re/modeling Gender" (2003) 18 Berkeley Women's LJ 15 at 15-16, n 2.

4 Human Rights Commission To Be Who I Am: Report of the Inquiry into Discrimination Experienced by Transgender People (2007) [Transgender Report] at 13; Aids Foundation "Pacific Island Sexual Minority Gathering" (19 October 2007) Scoop <www.scoop.co.nz>.

5 See generally Tess Lomax "Whakawahine - a Given or Becoming?" in Jessica Hutchings and Clive Aspin (eds) Sexuality and the Stories of Indigenous People (Huia Publishers, Wellington, 2007) at 82; and Niko Besnier and Kalissa Alexeyeff (eds) Gender on the Edge: Transgender, Gay, and Other Pacific Islanders (University of Hawai'i Press, Honolulu, 2014).

6 For an excellent summary of different legal and theoretical positions on this, see Laura Grenfell "Making sex: law's narratives of sex, gender and identity" (2003) 23 LS 66 at 91-100. For a trans perspective which rejects the distinction between sex and gender, see Dylan Vade "Expanding Gender and Expanding the Law: Toward a Social and Legal Conceptualization of Gender that is More Inclusive of Transgender People" (2005) 11 MIJGL 253 at 278-284. 
gender is the more socially and culturally relevant identity. I use the words "trans woman" and "trans man" where relevant. "Trans" is an adjective, which describes one aspect of a person's identity - a trans woman is a woman who was assigned male at birth. ${ }^{7}$ Some trans people (and some people who are not trans) do not identify as either male or female. These identities include nonbinary, genderqueer, androgynous, bigendered and non-gendered. I use the words "they" and "their" as singular pronouns rather than the more conventional "he or she" and "his or her", to acknowledge and respect this range of identities. ${ }^{8}$

Trans people are frequently subjected to medical and legal scrutiny in order to achieve recognition of their sex/gender. This high standard is often impossible to attain, leaving people with identity documents that do not match their identity. The process has been simplified for passports and for the drivers' licence register in New Zealand. However, the law for changing sex markers on birth certificates remains restrictive. It is governed by s 28 of the Births, Deaths, Marriages, and Relationships Registration Act 1995 (BDMRRA). In this article I argue that the medical model of sex that this section is based on is out-dated, and that $\mathrm{s} 28$ should be reformed so that it is based on self-identification.

Another group who may not identify with the sex on their birth certificate is intersex people; that is, people who are "born with a reproductive or sexual anatomy that doesn't seem to fit the typical definitions of female or male". 9 A small number of such people are recorded as "indeterminate" at birth, but most are assigned either male or female by doctors. ${ }^{10}$ It is possible for intersex people to correct the sex marker on their birth certificate to be intersex rather than male or female, using s 85 of the BDMRRA. There has been at least one successful application under this section. It was required that the applicant prove that the sex they were assigned on their birth certificate was an error and that they should have been recorded as "indeterminate". ${ }^{11}$ This is very difficult to prove.

For the majority of intersex people, s 85 will not apply, so they will have to use s 28 in order to change the sex on their birth certificate. ${ }^{12}$ Many of the criticisms I raise in relation to trans people

7 Serano, above $\mathrm{n} 1$, at 29.

8 "They" and "their" have long been used as pronouns when the gender of the person in question is either unkown or irrelevant. See for example, Catherine Soans "Faceoff: 'he', 'he or she', 'he/she', 's/he' versus 'they'" (6 June 2012) Oxford Words Blog 〈blog.oxforddictionaries.com>. Addtionally, many people who do not identify as either male or female use "they"/"their" to refer to themselves. See Lee Airton "Why Focus on Singular They?" They Is My Pronoun <theyismypronoun.wordpress.com>

9 Intersex Society of North America "What is intersex?" Intersex Society of North America <www.isna.org>.

10 Transgender Report, above $\mathrm{n} 4$, at 7.32 and 7.38 .

11 Human Rights Commission Human Rights in New Zealand: Ngā Tika Tangata O Aotearoa (2010) at 313.

12 Transgender Report, above n 4, at [7.26] 
have similar implications for intersex people. ${ }^{13}$ There are, however, no available cases about intersex people using s 28 so this is not part of my analysis. There may also be different or additional criticisms from an intersex perspective. One such criticism relevant to intersex people (and some trans people) is that there is no option of changing to "indeterminate" or any other alternative that is not male or female. The possibility of a third option for people (whether intersex or not) on birth certificates is outside the scope of this article, however, I do recognise that having more than two options is an essential aspect of self-identification. ${ }^{14}$ Also outside the scope of this article is whether to remove sex markers on birth certificates entirely. ${ }^{15}$

In this article I argue that the medical model which underpins s 28 should be rejected in favour of a self-identification model. Section 29, which applies to minors, should also be reformed, but is beyond the scope of this article. Part II explains that correct sex markers on birth certificates matter to trans people, because if changed they can be used as an affirmation of their identity in various contexts. In Part III, I describe the three major approaches to legal recognition of sex: biological, in which sex is defined by chromosomes, gonads and genitals, and is fixed at birth; medical, in which sex is defined by medical experts and changeable by sufficient medical treatment; and selfidentification, in which sex is defined by individuals themselves.

New Zealand's current law is described in Part IV. It requires that as a result of medical treatment, the applicant's body conforms sufficiently to that of a person of the "nominated sex". Case law has established that this does not necessarily require surgery, although some degree of medical intervention, at least in the form of hormones, is required. Part V critiques this approach because of its reliance on the medical model of sex. This model relies on harmful social norms about gender and requires medical intervention which is either unattainable or undesirable for many trans people. This means that legal recognition is frequently out of reach. Additionally, by requiring medical intervention, this approach breaches human rights.

In the last Part, I argue that New Zealand should adopt an approach based on self-identification for sex markers on birth certificates, as Argentina has done. This would be consistent with New Zealand's current approach to sex markers on passports and drivers' licences, which in both cases is based on self-identification.

\section{SEX MARKERS ON BIRTH CERTIFICATES MATTER}

Unlike many countries, New Zealand does not have any official identity documents. ${ }^{16}$ A birth certificate is simply evidence that a birth occurred and in fact contains a disclaimer that, "this

13 At [7.26].

14 See Spade, above n 3, at 29.

15 See Dean Spade "Documenting Gender" (2008) 59 Hastings LJ 731 at 802-804 and 806.

16 Transgender Report, above n 4, at [6.4]. 
certificate is not evidence of the identity of the person presenting it". ${ }^{17}$ The Human Rights Commission's (HRC) 2007 report To Be Who I Am (the Transgender Report) was the first inquiry into trans experiences in New Zealand. It heard from over 200 trans people. It found that despite the disclaimer that birth certificates are not proof of identity, in practice they do have such a role. The report found that "documents issued by the state assist most people to verify their identity and most people refer to these documents as 'forms of identity"'. ${ }^{18}$ Specifically, the ability to change the sex marker on birth certificates was important to trans people: ${ }^{19}$

An amended birth certificate is often treated as proof of a person's sex. A trans person can then rely on the birth certificate for a variety of purposes, including establishing identity.

The Transgender Report found that there were barriers to changing the sex marker on birth certificates and that this was an issue for trans people: ${ }^{20}$

On the one hand, the difference between the sex recorded on a birth certificate and how a trans person presents often results in suspicion and/or discrimination. On the other hand, the majority of trans people were unable to comply with the statutory test for change of sex on a birth certificate, which might help to prevent such suspicion or discrimination.

For example, people have been required to produce birth certificates to letting agencies ${ }^{21}$ and to prospective employers $^{22}$ in order to verify their identity. When the sex marker does not match a person's identity, this can result in discrimination against the person concerned.

In addition, birth certificates often act as a gateway to correcting a person's sex classification in institutions such as banks, hospitals and universities. ${ }^{23}$ A corrected birth certificate can facilitate the correction of sex/gender records in these other contexts, while if unchanged it can act as a barrier and source of discrimination.

The introduction of a self-identification approach to the sex marker on passports has, to some extent, reduced the relevance of birth certificates. ${ }^{24}$ It is no longer necessary to have an amended

17 Department of Internal Affairs "Certificate and Printout: Frequently Asked Questions" Department of Internal Affairs <www.dia.govt.nz>.

18 Transgender Report, above $\mathrm{n}$ 4, at [6.4].

19 At [8.9].

20 At [6.24].

21 At [4.15]

22 At [3.45].

23 At [3.30].

24 Elisabeth McDonald and Jack Byrne "The Legal Status of Transgender and Transsexual Persons in Aotearoa New Zealand" in Jens Scherpe (ed) The Legal Status of Transsexual and Transgender Persons 
birth certificate in order to change the sex marker on a passport, as it was previously. ${ }^{25}$ Passports are accepted in most contexts for identifying purposes. The new RealMe system of identification, which is used by all government departments and agencies, accepts passports as a basis of recognition. ${ }^{26}$ On a day-to-day level, passports and drivers' licences are much more commonly used forms of identification than birth certificates. However, passports need to be renewed every five years, ${ }^{27}$ a somewhat inconvenient and expensive process for people who do not intend to travel. Birth certificates, by contrast are a permanent form of documentation. Because of this, they are still the most important identity document. ${ }^{28}$

Additionally, despite the shift towards acceptance of passports to verify identity, there are some situations where birth certificates are the only relevant document. For example, a recent policy change has enabled trans prisoners who have changed the sex on their birth certificate to be housed in a prison that reflects their sex. Those who have not corrected their birth certificate will initially be housed in a prison that reflects the sex on their birth certificate. They must apply to the Chief Executive of the Department of Corrections to be housed in a prison that reflects their gender, with such cases being decided on a discretionary basis. Prisoners who have not changed their birth certificate and who are serving sentences or facing charges for serious sexual offending are not able to apply to be housed in the correct prison. ${ }^{29}$ This is discriminatory on the basis of whether a birth certificate has been changed, which illustrates their continued relevance. ${ }^{30}$

Another example of the importance of corrected birth certificates is that the recorded sex of a parent on their child's birth certificate is determined according to the parent's birth certificate. The Transgender Report heard from a trans man who was told he could not be registered as his child's

(Intersentia, Cambridge) (forthcoming) at 544-545. See Part V of this article for discussion of the passport policy.

25 Department of Internal Affairs "Information about Changing Sex / Gender Identity" New Zealand Passports <www.passports.govt.nz>.

26 New Zealand Government "Getting started with RealMe" RealMe <www.realme.govt.nz>.

27 Department of Internal Affairs "Five year passports - some important information" New Zealand Passports <www.passports.govt.nz>. It has recently been announced that the validity of passports will be extended to 10 years, see Peter Dunne "10-year passports enable reduction in annual cost" (25 May 2015) Beehive <www.beehive.govt.nz>.

28 McDonald and Byrne, above n 24, at 544

29 Anne Tolley "Prison changes to increase rehab and safety" (25 September 2013) Beehive: the official website of the New Zealand Government <www.beehive.govt.nz〉.

30 See JustSpeak "Transgender prisoner press release" (4 April 2014) JustSpeak <justspeak.org.nz> . 
father unless he changed the sex marker on his own birth certificate to male. ${ }^{31}$ There may be a similar issue where birth certificates are relevant to the sex recorded on a death certificate. ${ }^{32}$

Perhaps most importantly, having a birth certificate that reflects a person's gender is an important affirmation of identity in itself. ${ }^{33}$ The Transgender Report quotes one respondent as saying: "My birth certificate is fixed as the world judged me when I couldn't speak for myself."34 Birth certificates symbolise citizenship and so correct sex markers on birth certificates also symbolise recognition and belonging.

\section{LEGAL MODELS FOR CHANGING SEX ON BIRTH CERTIFICATES}

Legal approaches to sex have varied across time and across jurisdictions. Franklin Romeo has classified these into three broad models in the United States context: the biological model, the medical model and the self-determination model. ${ }^{35}$ It should be noted both that this classification was in the context of litigation (regarding discrimination, healthcare and privacy) rather than identity documents, and that self-identification was discussed as a potential new model that did not yet exist in United States case law or legislation. In this Part, I briefly describe each of these models. I relate these models to the New Zealand context in the following Part.

\section{A The Biological Model}

The biological model is the most restrictive approach. The English case of Corbett $v$ Corbett ${ }^{36}$ in 1970 was the foundational Common Law case regarding the validity of marriages involving trans people. ${ }^{37}$ It was followed in several other jurisdictions. ${ }^{38}$ It found that chromosomes, genitals and gonads were determinants of sex for the purposes of marriage.$^{39}$ Ormrod $\mathrm{J}$ ruled that "marriage is a relationship which depends on sex and not on gender", ${ }^{40}$ and that it was impossible to change one's

\footnotetext{
31 Transgender Report, above $\mathrm{n} 4$ at [4.12]

32 McDonald and Byrne, above n 24, at 545, n 70.

33 Transgender Report, above $\mathrm{n}$ 4, at [6.2].

34 At [6.20].

35 Franklin Romeo "Beyond the Medical Model: Advocating for a New Conception of Gender Identity in the Law" (2005) 36 Colum Hum Rts L Rev 713.

36 Corbett v Corbett (Otherwise Ashley) [1970] 2 All ER 33.

37 Grenfell, above n 6, at 69.

38 Grenfell, above n 6, at 74-78.

39 Corbett, above n 36, at 47 and 48.

40 At 49.
} 
sex even by surgically removing and reconstructing genitals. ${ }^{41} \mathrm{He}$ also found that marriage required the capacity for "natural" heterosexual intercourse, and that this was impossible with an "artificial cavity". 42

While the Corbett decision related to marriage, the reasoning underpinning it continues to be followed in several jurisdictions in relation to birth certificates. Often this is characterised by a lack of legislative provision to enable a change of sex marker. ${ }^{43}$ For example, there are three states in the United States that do not allow sex markers on birth certificates to be changed, one of which has an express prohibition. ${ }^{44}$ There are also 14 countries in Europe which do not allow legal gender recognition for trans people at all. ${ }^{45}$

\section{B The Medical Model}

In many countries, the biological model has been rejected in favour of the medical model, which acknowledges the possibility of changing sex in some circumstances. ${ }^{46}$ As Romeo describes it, this model relies on medical evidence (which can be psychological, or physical, or both), "to establish gender transgression as legitimate and therefore worthy of recognition and protection under the law". ${ }^{47}$ There is a spectrum of approaches both between and within jurisdictions that fall under the medical model.

At its most restrictive, recognition under this model is only available to "post-operative" trans people; that is, people who have surgery to reconstruct their genitals. Australian academics Laura Grenfell and Anne Hewitt call this a "sex as congruent anatomy and psychology" model. ${ }^{48}$ This approach exists for birth certificates in many jurisdictions, including almost all American states where changing the sex marker is possible, ${ }^{49}$ and most Australian states. ${ }^{50}$ Of the 35 countries in Europe where a legal change of sex is possible, 20 require surgery. ${ }^{51}$

41 At 47 .

42 At 49.

43 Laura Grenfell and Anne Hewitt "Gender Regulation: Restrictive, Facilitative or Transformative Laws?" (2012) 34 Syd LR 761 at 771-772.

44 The states are Idaho, Ohio and Tennessee. Tennessee has an express prohibition. Lambda Legal "Changing Birth Certificate Sex Designations: State by State Guidelines" Lambda Legal <www.lambdalegal.org>.

45 Transgender Europe "Trans Rights Europe Map 2014" (15 April 2014) Transgender Europe $<w w w . t g e u . o r g>$.

46 Grenfell, above n 6, at 79-86

47 Romeo, above n 35, at 724

48 Grenfell and Hewitt, above n 43, at 766-769.

49 There are 52 authorities that issue birth certificates in the United States. As of 2008, 19 had no official rule but allow the change in practice. The other 30 specifically authorised the changing of sex markers: Spade, 
At the other end of the medical model spectrum is an approach which "gives primacy to behaviour and psychology and considers anatomy to be of secondary relevance".52 Grenfell and Hewitt do not consider this to be part of the medical model, describing it instead as "transformative". ${ }^{53}$ However they cite the Australian passport policy, which requires medical evidence of "appropriate clinical treatment" 54 as an example of this approach. They argue that this requirement could include counselling and other therapy, suggesting a more psychological focus. ${ }^{55}$ According to the Australian Passport Office, the "appropriate clinical treatment" does not have to be specified so it is left up to the doctor to decide. ${ }^{56}$ In my view, the fact that any form of medical evidence is required situates this approach within the medical model, despite its potentially more flexible requirements than medical models that require surgery.

\section{The Self-Identification Model}

The third model allows legal recognition of a person's sex based on self-identification. This approach is grounded in self-determination; that is, the idea that a person should be able to determine their own sex/gender for all purposes, and that gender is "a healthy and legitimate expression of a person's identity". ${ }^{57}$ Self-identification, at least for the purposes of this article, refers more specifically to the ability to identify as one chooses on legal documents. ${ }^{58}$ Under this model,

above $\mathrm{n}$ 15, at 767-768. These numbers have not significantly changed, see Lambda Legal, above n 44 . All of the jurisdictions that allow the change require surgery, except Oregon, Washington, Vermont and New York States, and the District of Columbia: Mary Emily O'Hara "AMA Says Transgender People Shouldn't Require Surgery to Change Their Birth Certificate" (12 June 2014) Vice News <news.vice.com>.

50 Surgery to alter reproductive organs is required in New South Waltes, the Northern Territory, Queensland, Tasmania and Victoria. South Australia and Western Australia require a "medical or surgical procedure ... to alter the genitals". See Australian Human Rights Commission Sex Files: the Legal Recognition of Sex in Documents and Government Records (2009) at 16-17. See Grenfell and Hewitt, above n 43, at 773-778 for how the Western Australia and South Australia laws have been interpreted. The Australian Capital Territory changed its legislation in 2014, to require "appropriate clinical treatment". See Births, Deaths and Marriages Registration Act 1997 (ACT).

51 Transgender Europe, above n 45.

52 Grenfell and Hewitt, above n 43, at 769.

53 At 762 .

54 Australian Passport Office "Sex and Gender Diverse Passport Applicants" Australian Passport Office <www.passports.gov.au>

55 Grenfell and Hewitt, above n 43, at 772.

56 Australian Passport Office, above n 54.

57 Romeo, above n 35, at 739

58 Romeo uses "self-determination" because his article is about gender recognition more broadly, above n 35. The other authors cited in this article tend to be discussing identity documents so use "self-identification". 
legal recognition is based solely on a person's identity and does not require any medical (or any other) evidence.

Dean Spade, a trans activist, lawyer and academic, describes self-identification in the following terms: ${ }^{59}$

I would like people to have the freedom to determine their own gender identity and expression ... And I

would want no person to be required to show medical or psychiatric evidence to document that they are

who and what they say they are. I would like self identification to be the determining factor for a

person's membership in a gender category to the extent that knowledge of the person's membership in

such a category is necessary.

The self-identification model is illustrated by Argentina's Gender Identity Law 2012, ${ }^{60}$ which has been praised by activists around the world. ${ }^{61}$ Article 4 requires that for a person's sex to be amended on their birth certificate and national identity card: they have to be at least 18 (there is a separate process for minors); submit a request to the relevant authority; and provide a new first name that they want to be registered under. The law is explicit that: ${ }^{62}$

In no case will it be needed to prove that a surgical procedure for total or partial genital reassignment,

hormonal therapies or any other psychological or medical treatment has taken place.

This emphasis on not requiring medical evidence is key to self-identification. The very straightforward administrative procedure, ${ }^{63}$ rather than a court process, also illustrates that this law is based on self-identification.

\section{THE NEW ZEALAND LEGISLATION AND CASE LAW}

In New Zealand, the process for changing sex markers on birth certificates is governed by s 28 of the BDMRRA and has been clarified by case law, especially the Michael decision. ${ }^{64}$ The current legal position is somewhere in the middle of the spectrum of medical models described in the previous Part, because it requires some degree of medical intervention, but not necessarily surgery.

59 Spade, above n 3, at 29.

60 Ley No 267439 May 2012 (AR) (translated ed: Alejandra Sardá (translator) "Argentina's Gender Identity Law" Global Action for Trans Equality <transactivists.org>) [Gender Identity Law 2012 (Argentina)].

61 See for example Transgender Europe Legal Gender Recognition in Europe Toolkit (2013) at 49-54; Jack Byrne License to Be Yourself: Laws and advocacy for legal gender recognition of trans people (The Open Society Foundations, New York, 2014) at 9, 17, 23, 24, 41 and 43-45; and Aotearoa New Zealand's Sexual Orientation, Gender Identity and Intersex (SOGII) UPR Coalition 2013 "Submission from the Sexual Orientation, Gender Identity and Intersex (SOGII) UPR Coalition 2013" at [13].

62 Gender Identity Law 2012 (Argentina), art 4.

63 Article 6.

64 "Michael" v Registrar-General of Births, Deaths and Marriages (2008) 27 FRNZ 58 (FC) [Michael]. 
When the BDMRRA was passed, New Zealand courts had already adopted the medical model of sex in the context of marriage in $M v M^{65}$ and Attorney-General $v$ Family Court at Otahuhu. ${ }^{66}$ In $M$ $v M$, the court found a 12-and-a-half year marriage between a cisgender man and a trans woman was valid. Judge Aubin rejected Corbett, and concluded: ${ }^{67}$

In so far as these proceedings come down in the end to the definition of "woman", there is no medical

evidence in the case which is persuasive against the view that genetic considerations can be displaced by

events occurring in the course of the person's life that cumulatively take that person out of the sexual

category into which he or she was born through a state of limbo and into the haven of the opposite sex.

Despite this relatively progressive approach to marriage, the courts had, some years earlier, been unable to take a similar approach to birth certificates. The case of $R e T$ had found that changing the sex marker was not possible (except in the case of mistake at birth) because there was no statutory provision to enable such a change. ${ }^{68}$

There is now a statutory provision in s 28 of the BDMRRA. The BDMRRA was introduced in 1989 to consolidate and amend the existing births, deaths and marriages legislation. The clauses that became s 28 were the most contentious aspect of the Bill. ${ }^{69}$ As introduced, the Bill required that an applicant "has undergone surgical and medical procedures that have effectively given the person the physical conformation of a person of the opposite sex". ${ }^{70}$ However, the Select Committee thought this standard was too high, and so the provision was amended several times. ${ }^{71}$ The change in wording was summarised by MP Richard Northey during the third reading: ${ }^{72}$

The select committee ... recognised that it was principally a psychological, rather than a surgical, matter of identity, and that to require people to go through the full gamut of very expensive surgery in order simply to have themselves recorded on their birth certificate as being the sex with which they identify was inappropriate.

Most of s 28 is straightforward. As a preliminary point, it should be noted that s 28 actually requires that a person is "not a person of the nominated sex", ${ }^{73}$ and that the person has assumed the

65 Mv M(marriage: transexuals) [1991] NZFLR 337 (FC).

66 Attorney-General v Family Court at Otahuhu (1994) 12 FRNZ 643 (HC).

$67 M v M$, above n 65 , at 348 .

$68 \operatorname{Re} T$ [1975] 2 NZLR 449 (SC).

69 (15 May 1990) 507 NZPD 1356 and (20 March 1991) 513 NZPD 940.

70 Births, Deaths, and Marriages Registration Bill 1989 (193-1), cl 29(1)(b)(ii).

71 See Michael, above n 64, at [41]-[51] for a thorough discussion of the legislative history.

72 (28 March 1995) 547 NZPD 6465

73 Section 28(3)(b) (emphasis added). 
"gender identity of a person of the nominated sex"74 and wishes that sex to appear on their birth certificate. ${ }^{75}$ Prima facie, this wording suggests that sex is biological and unchanging, and that it is gender identity, rather than sex, can change under a medical model.

However, there are several reasons that the current interpretation of the legislation suggests a medical rather than biological approach to sex. First, the phrase "the gender identity of a person of the nominated sex" suggests that each sex has a corresponding gender identity (and that each gender identity has a corresponding sex), and that these will be congruent. Secondly, it is "sex" that is recorded on birth certificates, and it is "sex" that is changed by the s 28 process. Finally and most relevantly, judges generally read this provision merely as a repetition of s 28(3)(a)(i), that a person's birth certificate records the person as being of a sex opposite to the nominated sex, rather than treating it as an additional requirement. ${ }^{76}$ In keeping with this, my critique of the section proceeds on this basis that s 28 sets up a medical, rather than biological, approach to sex.

My focus in this article is on s 28(3)(c)(i), which contains three limbs that must each be satisfied "on the basis of expert medical evidence". The first limb requires that the applicant "has assumed (or has always had) the gender identity of a person of the nominated sex". ${ }^{77}$ This requirement has never been contentious. The second limb requires that the applicant: ${ }^{78}$

... has undergone such medical treatment as is usually regarded by medical experts as desirable to enable persons of the genetic and physical conformation of the applicant at birth to acquire a physical conformation that accords with the gender identity of a person of the nominated sex.

This "physical conformation" requirement is discussed in more detail below. The third limb requires that "as a result of the medical treatment undertaken, [the applicant will] maintain a gender identity of a person of the nominated sex". ${ }^{79}$ This requirement is rarely at issue, although in one case where the applicant's transition was relatively recent there was more emphasis on this. ${ }^{80}$

74 Section 28(3)(b)(i).

75 Section 28(3)(b)(ii)

76 For example Michael, above n 64, at [56]-[57] and [84]-[85]; Re C-DCT [2012] NZFC 10036 at [6]-[7]; H $v$ Registrar-General of Births, Deaths and Marriages FC Waitakere FAM-2009-090-002000, 21 September 2010 [H] at [21]-[22]; Kearney v Registrar-General of Births, Deaths and Marriages of Auckland [2013] NZFC 4805 [Kearney] at [7] and [15]; and KRM v Registrar-General of Births, Deaths and Marriages of Wellington FC New Plymouth FAM-2009-043-000082, 1 April 2009 [KRM] at [4]. MMT v R-GBDM [2012] NZFC 3533 [MMT] is the only case where the distinction is made clear, at [9].

77 Section 28(3)(c)(i)(A)

78 Section 28(3)(c)(i)(B).

79 Section 28(3)(c)(i)(C) (emphasis added).

$80 H$, above n 76, at [26]-[27] 
The interpretation of s 28(3)(c)(i)(B) was uncertain until the 2008 Michael decision. Many submitters to the Transgender Inquiry in 2007 thought that this physical conformation requirement: ${ }^{81}$

... meant that they must have had "full gender reassignment surgery". A number were given this advice by staff at the Department of Internal Affairs or at their local Family Court. Trans people said the statutory test was unfair and problematic given the reality that most will never be able to access the full range of surgical procedures.

The Michael case arose partly in response these concerns. ${ }^{82}$ At issue in the Michael case was: ${ }^{83}$

... at what point short of complete gender reassignment surgery a person's physical appearance has changed such that it "accords with the gender identity of a person of the nominated sex" [and] [m] ore particularly, whether an applicant must have undergone surgery to alter their genitals to satisfy that test[.]

Judge Fitzgerald approached this section by looking carefully at the wording. He found that "medical" was defined in s 2 of the BMDRRA as including psychological and surgical treatment, and could also include hormone treatment. ${ }^{84}$ "Physical conformation", he said, "refers to the structure or appearance of the applicant's body or physical characteristics". ${ }^{85} \mathrm{He}$ said: ${ }^{86}$

I do not think it appropriate or relevant to talk in terms of "thresholds" or "points on the continuum of surgical treatments" in a generalised way in cases under the section. I do not believe Parliament intended there be a standardised test to apply to all applicants and to do so would be to misunderstand transsexualism and the treatment for it. ... Just how much surgery [the applicant] needs to have had is determined on a case by case basis by reference to the evidence in the particular case, including that of the medical experts.

Thus Judge Fitzgerald held that "full" surgery is not required, but indicated that some degree of surgery is necessary. On the facts of the case, he decided that a combination of psychological counselling, continuous hormone therapy for four years and a bilateral mastectomy were sufficient to meet the test in s 28.87

81 As reported in the Transgender Report, above $\mathrm{n}$ 4, at [6.21].

82 Michael, above n 64, at [3]-[4], and [108]-[111].

83 At [71].

84 At [62].

85 At [66].

86 At [72].

87 At [88]-[90]. 
In terms of the words "usually regarded by medical experts as desirable", Judge Fitzgerald found that this: 88

... means the assessment of what is desirable is that of a group or consensus of medical experts, rather than the opinion of an individual medical expert. The test is not what the applicant considers to be desirable for him/her to achieve personal comfort with, or physical conformity to, their nominated gender identity.

Rather:89

The focus of the legal test is the nature of the medical (psychological and surgical) treatment received and [its] effect on the degree to which the applicant's physical conformation accords with that of the nominated gender.

In one recent case, $\operatorname{Re} C-D C T$, the Court took a different approach and held that: ${ }^{90}$

It is abundantly clear that the point at which treatment means a successful gender reassignment really comes down to a matter of individual choice and individual comfort.

This emphasis on an individual's needs is an important shift away from the idea of medical consensus in the Michael case. It is important to note, however, that $\operatorname{Re} C-D C T$ is the only case which has taken this approach, and it is somewhat stretching the words of the section.

The HRC's Human Rights in New Zealand report raised concerns about the interpretation of the physical conformation requirement, particularly in relation to trans women. It pointed out that Michael focused on the irreversible chest surgery, and that there was no equivalent procedure for trans women, who generally develop breasts through hormonal treatment rather than surgery. ${ }^{91}$ Additionally, "the Commission has been informed of other decisions where trans women have been required to show evidence of full sex-reassignment surgery". ${ }^{92}$ This suggests an inconsistent interpretation, with the Court requiring surgery in some cases but not others.

There are four subsequent cases where trans women were successful in their applications despite having undergone no surgery. However, two of the applicants said they wanted surgery but could not afford it, ${ }^{93}$ one was on the waiting list, ${ }^{94}$ and the other was about to undergo surgical

88 At [63] (emphasis added)

89 At [70].

$90 \operatorname{Re} C-D C T$, above n 76, at [14].

91 Human Rights Commission, above n 11 at 319.

92 At 319. This was not the outcome in any of the available cases, however.

93 Basingerv Registrar General [2013] NZFC 3562 [Basinger] at [6]; and MMT, above n 76, at [7].

94 DAC v Registrar General Births Deaths \& Marriages [2013] NZFC 1998 [DAC] at [13] 
treatment. ${ }^{95}$ Combined, these cases suggest that desire for surgery, if not actual plans for it, is considered to be a relevant factor. This presents a barrier for the large number of trans people, especially trans women, who never intend to have any surgery.

The information on the Department of Internal Affairs (DIA) website sets out the legislation and the Michael decision. It stresses that decisions are made on a case-by-case basis and that: ${ }^{96}$

... every applicant does not have to go through full reconstructive surgery to meet the test, although

some may do. The level of surgery required for each person will be particular to each person[.]

The reference here to the "level of surgery" suggests that some surgery is required. This is inconsistent with the recent case law discussed above.

The uncertainty about whether surgery is required is a problem for people who want to change the sex on their birth certificate. It is not appropriate that the level of intervention required is found in case law rather than clear legislation. The Transgender Report noted that a submitter had spent $\$ 2,000$ on legal fees to go through this process. ${ }^{97}$ Section 28 should be reformed in order to avoid this complexity.

\section{CRITIQUE OF S 28 AND THE MEDICAL MODEL OF SEX}

In the previous Part, I outlined s 28 and discussed the uncertainty regarding what level of medical intervention is required. This Part critiques s 28 more deeply by outlining the problems with the medical model of sex as it applies in this context. Regardless of the nature or degree of medical or surgical intervention required by judges, my argument is that the requirement for medical evidence at all is problematic. I discuss two major reasons for this: first, expectations of medical intervention frequently do not align with the needs or experiences that trans people have, and secondly, the requirement for medical intervention breaches human rights.

\section{A The Gulf between the Medical Model and Lived Experience}

Romeo argues that the medical model of sex "does not serve the vast majority of gender nonconforming people." 98 In New Zealand, this is highlighted by how few people have made use of $\mathrm{s}$ 28. Between 1995 and 2007, 114 people made applications under this legislation. ${ }^{99}$ Between 2008 and 2013, 105 applications were received. ${ }^{100}$ This makes a total of 219 between 1995 and 2013.

$95 H$, above n 76, at [27].

96 Department of Internal Affairs "General information regarding Declarations of Family Court as to sex to be shown on birth certificates" Department of Internal Affairs <www.dia.govt.nz> at 3.

97 Transgender Report, above n 4, at [6.23].

98 Romeo, above n 35, at 731.

99 Transgender Report, above n 4, at [2.9].

100 McDonald and Byrne, above n 24, at 534, n 36. 
There is no definitive record of the number of trans people in New Zealand, because the census does not collect this information and no national studies have been done. However, it is suggested that there are "at least a few thousand" trans people in New Zealand. ${ }^{101}$ A 2012 survey reported that one per cent of high school students identified as transgender and a further three per cent as not sure of their gender, ${ }^{102}$ suggesting that the trans population might be much larger than previously thought.

My search of legal databases resulted in finding only 10 cases under s 28, out of those 219. All of the applicants in these cases were successful, and it is not clear how many applicants have been unsuccessful under this section. In any case, it is probable that people will only apply if they think they are likely to succeed. The gap between the 219 applications and the population of several thousand trans people shows that use of s 28 is not widespread - despite the barriers and discrimination that trans people face when their birth certificate is incorrect, as I outlined in Part II. In my view, the reason for this discrepancy is partly the uncertainty that I have already discussed, and partly financial and other barriers to accessing legal information. However, these are both underpinned by a bigger factor, which is that the medical model that s 28 is based on does not reflect the reality of trans lives.

Franklin Romeo describes the medical model as a system "that regulates gender non-conformity and predicates legal rights on access to healthcare". ${ }^{103}$ Both the regulation of gender non-conformity and the requirement of healthcare as a prerequisite to accessing legal rights are present in the wording and operation of s 28 . They are intertwined to a large extent, since requiring medical intervention is itself based on normative assumptions about trans identity.

Romeo has argued in the United States context that the medical model of sex sets up hypernormative standards of gender and fails to recognise lived experience and complexity. ${ }^{104}$ Courts recognise trans identity only when it conforms to expected standards; transgressive experiences of gender are fraudulent or illegitimate. ${ }^{105}$ The question is not whether the person has had the medical treatment appropriate for their needs, but whether the result is a "body and behaviour that sufficiently conform to normative gender standards so as to be considered legitimate in the eyes of the court". 106

101 At 535

102 TC Clark and others Youth'12 Overview: The health and wellbeing of New Zealand secondary school students in 2012 (University of Auckland, Auckland, 2012) at 25.

103 Romeo, above n 35, at 730 .

104 At 731

105 At 733

106 At 734 
Section 28 of the BDMRRA operates in a similar way. It gives medical "experts" (who are generally not trans) the power to scrutinise a person's body and experience in order to decide whether they have "really" transitioned to the "nominated sex". As I discussed in Part IV, what is "desirable" for each person to complete their transition is not defined by the person themselves, nor even by their doctor, but by a standard of what is "usually" considered desirable by the medical profession as a whole. ${ }^{107}$ Individual cases are decided not in isolation but with reference to precedent, usually the Michael case. Direct comparisons are not often made explicitly, however, in $A B$, the applicant was classified as "further along the continuum than the applicant in $R e$ Michael". 108

One of the major normative assumptions about trans people is that they want, need and can afford all available medical intervention (and that they will qualify for it and be able to access it). ${ }^{109}$ This is explicit in s 28 itself, and further emphasised in the case law. The Michael judgment sets out the "typical" course of treatment expected of trans people in a passage cited in several subsequent cases: $:^{110}$

There are typically four steps of treatment, namely psychiatric assessment, hormonal treatment, a period of living as a member of the opposite sex subject to professional supervision and therapy (the "real life experience"), and finally, in suitable cases, gender reassignment surgery. Surgical intervention takes many forms and, for a variety of reasons, is undertaken by different people to different extents.

This suggests that trans people who do not access the full range of medical intervention expected of them are unlikely to meet the physical conformation requirement of the BDMRRA. I have already discussed surgery. "Real life experience" is sometimes mentioned in the cases but not emphasised as a requirement ${ }^{111}$ - possibly because it is generally presumed to be met by applicants. In terms of psychological assessment, a diagnosis of gender identity disorder was mentioned in three cases, ${ }^{112}$ and gender dysphoria was diagnosed once. ${ }^{113}$ All of the other cases mention psychological

107 Michael, above n 64, at [63].

108 Re AB FC Auckland FAM-2009-004-001341, 16 November 2009 at [10].

109 Spade, above n 15, at 754-756.

110 Michael, above n 64, at [30]; quoted in $\operatorname{Re} A B$ above n 108, at [10]; and $H$ above $\mathrm{n} 76$, at [17].

$111 \operatorname{Re} A B$, above n 108, at [24]; DAC, above n 94, at [8] and [13]; H, above n 76, at [10], and [11]; Lucas v Registrar-General Births, Deaths and Marriages [2013] NZFC 6612 [Lucas] at [7]; Michael, above n 64 at [16] and [19]; and $M M T$, above n 76, at [4].

$112 A B$, above n 108, at [24]; $D A C$, above n 94, at [8]-[9]; $H$, above n 76, at [6]-[7].

113 Michael, above n 64, at [16]. 
assessment but do not use these labels. ${ }^{114}$ Similarly, in all of the cases the applicant had been undergoing hormonal treatment, intending to continue it permanently. ${ }^{115}$

The medical model presents a barrier for people who cannot access medical intervention to the degree required, whether this is due to expense, discrimination or the healthcare simply not being available. ${ }^{116}$ Most healthcare required by trans people is not publicly funded in New Zealand, and often trans people are excluded from healthcare that is available to other groups of people. ${ }^{117}$ For example, many trans people have to pay for their own psychological assessments (which seem to be required under s 28 , and are also frequently needed as a prerequisite to accessing hormones). ${ }^{118}$ The Transgender Report found that people were paying up to $\$ 1000$ for this assessment. ${ }^{119}$ Hormone treatment is not always accessible, ${ }^{120}$ and genital surgery is out of reach for most trans people, due to its high cost and very limited availability in New Zealand. ${ }^{121}$

Transition-related healthcare is a necessity for many trans people, and I do not wish to detract from the need for substantial reform in this area. ${ }^{122}$ However, even if trans people were able to access the healthcare they required, the more fundamental problem with legal recognition being based on medical intervention would remain. Some trans people have benefited from being recognised by the medical model of sex. ${ }^{123}$ Other trans people however, will never attain legal recognition from a system premised on medical authority over their bodies, either because it is impossible for them to express their identity and experiences in a way that fits this model, ${ }^{124}$ or

114 Basinger, above n 93, at [5] and [7]; C-DCT, above n 76, at [12]; Kearney, above n 76, at [10]; KRM, above n 76, at [10]; Lucas, above n 111 at [7]; and $M M T$, above n 76, at [5].

$115 \operatorname{Re} A B$, above n 108 at [6] and [8]; Basinger, above n 93 at [5] and [10]; C-DCT, above n 76, at [12] and [22]; $D A C$, above n 94, at [7]; $H$, above n 76, at [7] and [27]; Kearney, above n 76, at [4] and [10]; KRM, above n 76, at [7]; Lucas, above n 111, at [7]; Michael, above n 64, at [12]; and MMT, above n 76, at [4] and [9].

116 See generally Romeo, above n 35, at 734-738; and Spade, above n 15, at 751-759 for effects on low income people in the United States context.

117 Transgender Report, above n 4, at [5.36]-[5.37].

118 At [5.30].

119 At [5.21]-[5.25].

120 At [5.8], [5.17] and [5.71].

121 At [5.44]-[5.45] and [5.88]-[5.95].

122 See Transgender Report, above n 4, at ch 5 for discussion of inequalities and discrimination in healthcare for trans people in New Zealand.

123 See Spade, above n 3, at 30.

124 Jonathan L Koenig "Distributive Consequences of the Medical Model" (2011) 46 Harv CR-CL L Rev 619 at 627 and 629. 
because their political conception of their identity is so far removed from this model that they refuse to partake in it. ${ }^{125}$

Some trans people are politically opposed to the medical model, but navigate it successfully in order to attain healthcare or legal recognition. ${ }^{126}$ Spade describes this as "selective recitation" of one's experiences in a way that meets normative expectations. ${ }^{127}$ This includes emphasis on stereotypically gendered childhood experiences such as (for trans men) dressing up as a boy for Halloween, playing with trucks instead of dolls, and having short hair. ${ }^{128}$ It also includes a desire to "pass" as one's self-identified gender full-time. ${ }^{129}$ Spade himself rejects these narratives, but recognises the risk in doing so: "What if it means I'm not 'real'?"130

Spade explains the inconsistency between trans experience and normative expectations in the following description of his experience trying to get chest surgery: ${ }^{131}$

I was experiencing acutely the gulf between trans community understandings of our bodies, our experiences, and our liberation, and the medical interpretations of our lives. ... My quest for body alteration had to be legitimized by a medical reference to, and a pretended belief in, a binary gender system that I had been working to dismantle since adolescence. Later, as I contended with my own legal gender status and that of my clients, I would learn that not only medical treatment, but also legal rights and social services for trans people are dependent upon successful navigation of that medical system.

While the context is different, Spade's experiences illustrate the uncomfortable compromises many trans people make in order to attain recognition. It is impossible to know how many of the applicants in the available New Zealand cases were engaging in "selective recitation" of identity narratives. Given that legal recognition of their identity hinges on proving their "realness" to the courts, it is a logical strategy. The successful applicants could shape their narrative enough to fit the court's requirements, but this leaves out those for whom this is impossible, either due to political conviction or because their reality is just too different to normative expectations to be able to shape their experience in that way.

125 Koenig, above n 124, at 628-629.

126 Spade, above n 3, at 23; Koenig, above n 124, at 629; and Vade, above n 6, at 272-273.

127 Spade, above n 3, at 20.

128 At 20 and 24 .

129 At 21

130 At 20.

131 At $23-24$. 


\section{B The Medical Model is Inconsistent with International Law}

Legal recognition of gender identity is a human right in international law. This is set out in the Yogyakarta Principles, which were developed as an application of existing international human rights instruments, such as the United Nations Declaration of Human Rights (UNDHR) ${ }^{132}$ and the International Covenant on Civil and Political Rights (ICCPR), ${ }^{133}$ to rights in relation to sexual orientation and gender identity. ${ }^{134}$ In New Zealand, these principles have "become recognised as a useful statement of international human rights law". ${ }^{135}$ Yogyakarta Principle 3 states, ${ }^{136}$

Each person's self-defined sexual orientation and gender identity is integral to their personality and is one of the most basic aspects of self-determination, dignity and freedom. No one shall be forced to undergo medical procedures, including sex reassignment surgery, sterilisation or hormonal therapy, as a requirement for legal recognition of their gender identity.

One of the mechanisms for monitoring compliance with international human rights law is the United Nations' Universal Periodic Review (UPR). A submission was made to New Zealand's 2013 UPR by the Sexual Orientation, Gender Identity and Intersex (SOGII) Coalition, which was comprised of 11 organisations, including GenderBridge, Agender Christchurch, TransAdvocates and Intersex Trust Aotearoa. The submission pointed out that s 28 is in breach of Yogyakarta Principle $3,{ }^{137}$ and requested that the Government: ${ }^{138}$

... enable adults with intersex conditions and trans and other gender diverse adults to change the sex details on any official documentation to male, female or indeterminate based solely on the individual's self-identification, without any requirement for medical treatment and without the need to resort to a court process.

132 Universal Declaration of Human Rights GA Res 217 (1948)

133 International Covenant on Civil and Political Rights 999 UNTS 171 (opened for signature 16 December 1966, entered into force 23 March 1976).

134 International Commission of Jurists Yogyakarta Principles: Principles on the application of international human rights law in relation to sexual orientation and gender identity (March 2007) [The Yogyakarta Principles].

135 Human Rights Commission, above n 11, at 309

136 The Yogyakarta Principles, above n 134, at 11-12.

137 SOGII UPR Coalition, above n 61, at [8] and [12]

138 At $[\mathrm{f}]$. 
Concern about human rights breaches has often focussed on mandatory sterilisation as a requirement for obtaining legal recognition of gender identity. ${ }^{139}$ This amounts to a violation of the right to be free from torture and other cruel, inhuman or degrading treatment, in art 5 of the UNDHR and art 7 of the ICCPR. The emphasis of this concern is often the requirement for surgery, ${ }^{140}$ but it should be noted that hormonal treatment also frequently results in sterilisation. ${ }^{141}$ Laws that require hormone therapy as a prerequisite to legal recognition (which is effectively the situation under s 28) are therefore also in breach of human rights.

The SOGII UPR submission recommended that the Government: ${ }^{142}$

... remove any requirement to undergo or intend to undergo medical or surgical procedures, including

those that may result in sterilisation, as a prerequisite for changing sex details on a birth certificate or

other official document[.]

The recommendations in the SOGII submission were not included in the recommendations made to New Zealand by the Universal Periodic Review. However, the Government has indicated an intention to "follow up on these issues". 143

Spade writes that the medical model was in its time a progressive step forward for trans people because it offered some rights as opposed to none: "to some extent, the medicalization of trans identity was at one time a progressive step toward dignity and equality because it was preferable to total illegitimacy and criminality". ${ }^{144}$ The same is true in the New Zealand context: for those who have made use of it, s 28 has been an important piece of legislation, but there are now calls to reform this law. ${ }^{145}$ Given the problems inherent in a medical model of sex which I have outlined in this Part, it is time to move to a model based on self-identification rather than medical evidence. This is the focus of the next Part.

139 Juan Méndez Report of the Special Rapporteur on torture and other cruel, inhuman or degrading treatment or punishment (United Nations General Assembly, A/HRC/22/53, February 2013) at [38], [78], [79] and [88].

140 At [77].

141 Eli Coleman and others Standards of Care for the Health of Transsexual, Transgender and GenderNonconforming People (7th ed, World Professional Association for Transgender Health, [no location given], 2012) at 50.

142 SOGII UPR Coalition, above $\mathrm{n} 61$, at [e].

143 New Zealand Government "New Zealand Government Response to 2014 UPR recommendations" Human Rights Commission < www.hrc.co.nz> at [3].

144 Spade, above n 3, at 31-32.

145 SOGII UPR Coalition, above n 61, at [7]-[17] and [e]-[g]; and draft Member's Bill, prepared by members of the trans community and submitted to Louisa Wall MP, on file with author. 


\section{SELF-IDENTIFICATION FOR BIRTH CERTIFICATES IN NEW ZEALAND}

Self-identification is an appropriate standard for changing sex markers on birth certificates in New Zealand. This was demonstrated in the previous Part, where I discussed the ways that the medical model privileges the views of "experts" above the experiences of the individual concerned, and breach human rights. This Part points out that in addition to the arguments in favour of selfidentification that I have already discussed, self-identification on birth certificates would result in consistency with other identity documents. I then reject other reform options, outline how selfidentification would work and finally address potential criticisms of this reform.

\section{A Consistency with Drivers' Licences and Passports}

Self-identification already exists in New Zealand in two important contexts. The DIA changed its passport policy in 2012. Previously, a trans person who had not changed the sex details on their birth certificate could only change their passport sex marker to "X". Now, an applicant can choose the sex that appears on their passport (M, F, or X) even if this conflicts with the sex on their birth certificate. ${ }^{146}$ The New Zealand Transport Agency (NZTA) also changed its policy in 2013. While sex details do not actually appear on drivers' licences, they are kept in a register by NZTA, which is accessible by police officers. The options are now male, female or indeterminate. ${ }^{147}$ The New Zealand passport policy is thought to be the most progressive passport policy in the world. ${ }^{148}$

As discussed in Part II, passports are accepted as identity documents in most (but not all) contexts. It makes sense to have the same standard for birth certificates as for passports, as there is no material difference in their function as identity documents and not everyone has a passport or wishes to get one. ${ }^{149}$ Additionally, for the majority of people who do have both a passport and a birth certificate, it makes sense for these to be consistent.

According to the Transgender Report: ${ }^{150}$

The Department of Internal Affairs said the rationale supporting their transgender policies focused on the need for certainty and accuracy in the information recorded on the registers of births, deaths and marriages and on certificates issued on the basis of that information. Officials said: 'This need for

146 Department of Internal Affairs, above n 25.

147 New Zealand Transport Agency "Replacing or changing your licence" New Zealand Transport Agency <www.nzta.govt.nz>.

148 Byrne, above n 61, at 20-21.

149 The ACT Law Reform Advisory Council made this point when considering options for legislative reform in the ACT: ACT Law Reform Advisory Council Beyond the Binary: legal recognition of sex and gender diversity in the ACT (ACT Law Reform Advisory Council, LRAC 2, March 2012) at 39-40.

150 Transgender Report, above n 4, at [8.30]. 
certainty, however, is balanced to a certain extent, against an individual's right to identify themselves as they see fit.'

It further noted: ${ }^{151}$

There are legitimate and important state interests in ensuring that birth certificates and other similar documents accurate reflect the true details of a person's identity (such as their sex) to prevent the fraudulent or unlawful use of the document.

It is interesting that a restrictive approach to changing the sex marker on birth certificates is here characterised as certain and accurate, and contrasted with self-identification. The opposite is in fact true: laws which make it difficult to change one's birth certificate mean that there is inconsistency between a person's birth certificate, their recorded sex on other documents (for example, licences and passports), and their identity. This leads to more inaccuracy, confusion and inconsistency than a model based on self-identification would.

\section{B Inadequacy of Other Reform Options}

The Transgender Report recommended changing s 28(3)(c)(i) to require that the court: ${ }^{152}$

$\ldots$ is satisfied on the basis of expert medical evidence that the applicant ... (B) has taken decisive steps

to live fully and permanently in the gender identity of the nominated sex; and (C) will, as a result of

those decisive steps, maintain a gender identity of a person of the nominated sex.

Although this provision would have been a step forward prior to the Michael decision, it would be an insufficient remedy to the challenges that I have presented. Because it requires medical evidence, it is still based on the medical model, which privileges the views of "experts" above the experience of the people concerned, and continues the gatekeeping role of the medical profession. It is not at all evident that this would be a "robust and clear statutory test"153 as the HRC claims. "Decisive steps" would need judicial clarification in the same way that the current law has evolved through case law. It is not clear whether these have to be medical steps, although this is implied by the HRC's statement that such a provision would reflect the "broad range of medical steps that will be taken by most trans people". 154

An alternative option would be to leave the legislation as it is, and instead have the Principal Family Court Judge issue a practice note about how the section should be interpreted. ${ }^{155}$ This would

151 At [8.32].

152 At [9.33] (emphasis in original).

153 At [9.34].

154 At [9.35].

155 McDonald and Byrne, above n 24, at 567. 
have the benefit of avoiding the time, cost and potential controversy of legislative change. A practice note could set out the degree of medical evidence required. It could reflect and clarify the current case law, so that surgery is not required but some medical intervention (such as hormones) is. Alternatively it could go further and state that while medical evidence is required, it only needs to be evidence of the person's identity and not necessarily of any intervention. This would be stretching the wording of s 28 , which requires that the applicant "has undergone medical treatment". In any case, it would still mean that decisions about the validity of trans identity and experience were left to doctors and judges, rather than trans people themselves. It is therefore subject to the criticisms of the medical model that I have discussed Part V.

The legislative reform suggested by the HRC and the possibility of a practice note would both go some way in clarifying and confirming the existing law. The practice note option could potentially go beyond existing case law, however neither option remedies the fundamental flaws inherent in the medical model of sex, because both remain reliant on the presence of medical evidence. As discussed in Part V, the medical model undermines trans identities by privileging the opinions of medical professionals over trans people's own experiences of their bodies and their lives. The only way to remedy this fully is to reform the law so that it is based entirely on selfidentification.

\section{The Implementation of a Self-Identification Model to Birth Certificates}

Adopting a self-identification model would create more consistency between records. It would also allow trans people an important affirmation of their identity, and reduce the barriers for recognition in other contexts, as described in Part II. There are two examples that can be followed. The first is the DIA and NZTA policies described above. The other is the Argentinian law, which as discussed in Part III, is praised by activists internationally.

The DIA and NZTA policies require a statutory declaration by the applicant expressing which gender they want to be recorded as, and how long they have lived in that gender (although nothing turns on this second requirement). ${ }^{156}$ Each of these policies also includes a third option for people who do not identify as either of the binary genders ("X" and "indeterminate" respectively), ${ }^{157}$ and allow unlimited changes (although the DIA points out that multiple changes may cause issues when travelling internationally). ${ }^{158}$ Both of these policies conform to international best practice. ${ }^{159}$

156 Department of Internal Affairs, above n 25; and New Zealand Transport Agency, above n 147.

157 Department of Internal Affairs, above n 25; and New Zealand Transport Agency, above n 147.

158 Department of Internal Affairs, above n 25.

159 Byrne, above $\mathrm{n} 61$, at 20-21 discusses these policies. They also conform with the best practice set out by Transgender Europe, above n 61, at 57-59. 
Similarly, Argentina's Gender Identity Law provides an example of how this model can be applied to birth certificates. As already mentioned, it is generally seen as the most progressive gender recognition legislation. A similar law has recently passed in Denmark, ${ }^{160}$ and Malta is also considering this model. ${ }^{161}$ There are several proposed Bills in Ireland, one of which, the Gender Recognition Bill 2013, models the Argentinian law very closely. ${ }^{162}$ This Bill provides an illustration of how self-identification can be legislated for in a Common Law jurisdiction. ${ }^{163}$

Section 28 should be reformed so that it simply requires a statutory declaration of a person's sex. Statutory declarations must be in the form prescribed in sch 1 of the Oaths and Declarations Act 1957, and signed by an authorised person, such as a lawyer or Justice of the Peace. ${ }^{164}$ This would remove the need for medical evidence and significantly simplify the process. The authorised person would not determine the validity of the applicant's sex, but verify that the person had signed the statutory declaration.

\section{Responses to Potential Concerns}

Section 28 of the BDMRRA has not been debated in New Zealand since it passed in 1995. The recent DIA and NZTA policy changes do not seem to have provoked any criticism or backlash. As such, it is difficult to assess what the concerns might be raised about a model of self-identification in New Zealand. Some common concerns that have been raised internationally, and responses to them, are as follows.

One argument is that self-identification on birth certificates could lead to identity fraud. ${ }^{165}$ This overlooks that (binary) sex markers identify a person as being one person of roughly 50 per cent of the population and are not a useful form of identification. ${ }^{166}$ Fraud could be far more easily committed by changing one's name, which is straightforward to do by statutory declaration in New Zealand. ${ }^{167}$ In any case, fraud is a crime and would be treated as such if it arose. ${ }^{168}$ During the first

160 ILGA Europe "Denmark becomes the first European country to allow legal change of gender without clinical diagnosis" ILGA Europe <www.ilga-europe.org>.

161 Neil Falzon "A Proposed Gender Identity Act for Malta" (December 2010) Malta Gay Rights Movement <www.maltagayrights.org>.

162 Gender Recognition Bill 2013 (56) (introduced as Member's Bill by Deputy Snodaigh).

163 Byrne, above n 61, at 36.

164 Authorised people are set out in s 9 of the Oaths and Declarations Act 1957.

165 Transgender Europe, above n 61, at 60; and Kristin Wenstrom ""What the Birth Certificate Shows": An Argument To Remove Surgical Requirements from Birth Certificate Amendment Policies" (2008) 17 Law $\&$ Sex 131 at 154 .

166 Spade, above n 15 at $802-803$.

167 Department of Internal Affairs "Changing a Name" <www.dia.govt.nz>. 
year after the passage of Argentina's legislation, 3,000 people changed their identity documents with no reported cases of fraud. ${ }^{169}$

Another argument is that men would change their sex to female in order to access, gendersegregated spaces such as women's prisons or women's public toilets. ${ }^{170}$ Underlying this concern that people with "male" genitalia will be allowed in female spaces is an implicit fear that trans women are more likely to be physically or sexually violent towards other women, which is a baseless assumption. ${ }^{171}$ Additionally, arguments like this tend to shift the focus away from policies which actually make those spaces safer for women. ${ }^{172}$

Another concern is that people would "change back" to their "original" gender. ${ }^{173}$ This is reflected in s 28's requirement for permanency. ${ }^{174}$ Critics have failed to point out why this would actually be a problem. Most trans people do not "change back". ${ }^{175}$ More importantly however, if people do wish to change their identity more than once there should not be barriers to doing so. ${ }^{176}$ The Argentinian law explicitly recognises this (although subsequent changes require judicial authorisation). ${ }^{177}$ The analogy can again be made to name changes: divorced women frequently revert to their maiden name and this does not create any problems. ${ }^{178}$ There is no logical reason for sex markers to be treated any differently.

\section{CONCLUSION}

The provision for changing sex markers on birth certificates in s 28 of the BDMRRA does not enable the majority of trans people to make this change. As I have shown, birth certificates matter to trans people because they are an expression of identity and citizenship, and because birth certificates with the correct sex marker can facilitate recognition of identity in various settings. I have set out the three major legal approaches to sex: biological, medical and self-identification. Each of these is

168 Crimes Act 1961 ss 228, 240 and 241

169 Transgender Europe, above n 61, at 60.

170 Transgender Europe, above n 61, at 60; and Wenstrom above n 165, at 147.

171 Wenstrom above n 165, at 148 and 151; and Spade, above n 15, at 810 .

172 Wenstrom above n 165 , at 149.

173 Transgender Europe, above n 61, at 61; and Wenstrom above n 165, at 156.

174 Section 28(3)(c)(i)(C).

175 Wenstrom above n 165, at 156.

176 Byrne, above n 61, at 18-19; and Wenstrom above n 165, at 156.

177 Gender Identity Law 2012 (Argentina), art 8.

178 Wenstrom, above n 171, at 156-157. 
currently followed in different jurisdictions with regard to birth certificates. Argentina was the first country to adopt the self-identification approach, and others are looking to this example.

Section 28 of the BMDRRA is based on the medical model, because it requires medical evidence of physical conformity of the applicant's body to that of a person of the "nominated sex". Michael and other cases have established that surgery is not always required, however the degree intervention that is required remains unclear. While not all applicants in the available cases had undergone surgery, all expressed some degree of desire for it. Additionally, all of the applicants were undergoing hormone treatment and all had had some form of psychological assessment.

The medical model is based on normative expectations of trans experience. Some people's experiences fit these requirements, however many others cannot afford, cannot access or do not want medical intervention. Additionally, the current law is inconsistent with the right to selfdetermination of gender identity set out in Yogyakarta Principle 3, both by requiring medical evidence at all and by requiring hormone treatment, which frequently results in sterilisation. Reform options that are based on the medical model are insufficient to counter these critiques.

Self-identification already exists in New Zealand for passports and drivers' licences, and it makes sense to have a consistent approach. Accordingly, I have suggested that s 28 should be amended to simply require a statutory declaration as to the applicant's sex. Finally, I have demonstrated that potential concerns raised about the self-identification model are likely to be unfounded.

The reform of s 28 so that it is based on self-identification rather than the medical model would remove one of the barriers that trans people currently face in seeking legal recognition of their identity. It would be a significant improvement on the current law and allow many more people access to a corrected birth certificate. This would have a number of positive flow-on effects of trans identity being recognised and validated. However, any reform that occurs must take into account other criticisms of the current law, and must be done in consultation with trans, intersex, non-binary and other gender diverse communities. 
(2015) 46 VUWLR 